\title{
Examining the Data Analytics Skill Gap in Mid-Level Marketing Professionals, Driven by the Continuing Exponential Growth of Big Data
}

\author{
Richard J. Vaughan ${ }^{1 *}$ \\ ${ }^{1}$ College of Business, University of St. Francis, Joliet, USA \\ *Richard J. Vaughan, E-mail: rvaughan@stfrancis.edu
}

Received: July 25, 2017

Accepted: August 6, 2017

Online Published: August 16, 2017

doi:10.22158/jbtp.v5n3p267

URL: http://dx.doi.org/10.22158/jbtp.v5n3p267

\begin{abstract}
The purpose of this paper is to examine the impact of big data in the skill requirements of marketing professionals. Over 12,000 marketing job listings in the top six major marketing cities were researched to determine how many positions required big data analytics skills. $38 \%$ of big data's biggest impact is in marketing, advanced analytics are used in customer-facing marketing, sales and customer service departments. This research found 39\% of all marketing positions in the defined search criteria listed "big data" as a required skill in the combined six cities. It is interesting to note the relatively new term "big data" was cited 39\% and surpassed the term "Data", which was cited 35\% across all 12,796 positions.
\end{abstract}

\section{Keywords}

big data, marketing, analytics, chief data officer, required marketing skills

\section{Introduction}

Big data is exploding and marketing job requirements are reflecting the relatively new required skills and significantly widening talent gap. The era of "Big data" has clearly arrived; it refers to a collection of data sets so large and complex that it becomes difficult to process using traditional data processing applications.

The big data problem becomes significantly bigger when we take into account the predicted growth in the amount of data companies will produce: Data is growing faster than ever before and by the year 2020, Experts are predicting a 4,300 percent increase in annual data production, estimating 1.7 megabytes of new information will be created every second for every human being on the planet (Forbes.com, 2017).

Currently, companies on average use only a fraction of the data they collect and store. If a marketing company is already struggling to find skilled data analyst, the problem will accelerate exponentially as they begin to drown in the coming explosion of data in the next few years.

"There will be a shortage of talent necessary for organizations to take advantage of big data. By 2018, the United States alone could face a shortage of 140,000 to 190,000 people with deep analytical skills as well as 1.5 million managers and analysts with the know-how to use the analysis of big data to make effective decisions" (McKinsey \& Company, 2017).

This paper looks to examine the effect of big data in marketing job postings. Over 12,000 marketing job listings in the top six major marketing cities were researched to determine how many positions 
required big data analytics skills.

The actual term "big data" is very recent, the concept was coined by industry analyst Doug Laney in 2000, and the accepted definition of big data refers to the three V's, volume, velocity and variety. (Insights, Insights and Data, 2017).

Big data is usually associated with this three characteristic. Volume defines the amount of data created by organizations or individuals. Velocity defines the frequency at which data is generated, captured and shared. Variety refers to a proliferation of data types from social, machine-to-machine and mobile sources add new data types to traditional transactional data (Schmidt, 2012).

Big data's biggest impact (38.2\%) is in marketing, advanced analytics are used in customer-facing marketing, sales and customer service departments (Anon, 2017). However, big data alone does not translate to improve marketing results, the insights derived from big data, can have a significant impact on profitability. Insight from big data with a comprehensive marketing strategy can make a considerable impact in customer retention, acquisition, engagement and optimization performance. Big data can provide insight into where customers are located, what they want, how, when and where they want to be contacted. Big data can identify what influences customer's brand loyalty and how to increase repeat purchases. Big data's biggest impact maybe in determining the optimal marketing campaign spend across various channels, as well as continuously providing real time analytics on the programs overall performance and analysis.

Three critically important types of big data have been identified is paramount for marketing success. The primary category is customer data which include behavioral, attitudinal and transactional metrics from such sources as promotion campaigns, websites, surveys, points of sale, social media, online communities and loyalty reward programs. Operational data typically includes objective metrics that measure the quality of marketing processes relating to marketing operations, asset management, budgetary controls and resource allocation. The third is the financial systems; this category includes sales, revenue, profits and other objective data types that measure the financial health of the organization (Sas.com, 2017).

Frost and Sullivan's (2016) Annual Survey CEOs'Perspectives on Growth, Innovation and Leadership, surveyed over 300 CEOs and business leaders across the Americas, Asia Pacific, Europe and Africa. The CEO's surveyed identified strategic partnerships and big data as key to success and sustainable growth (Frost.com, 2017).

"As global economic ecosystems experience intense transformation driven by digitization and resulting change of focus from products to services, new opportunities for growth and innovation are emerging. However, leveraging these opportunities requires visionary leadership that can realize growth strategies and vision congruence", says Frost and Sullivan (2017) (Frost.com, 2017). That is the major finding of the 2017 executive survey. A strong majority of executives, 48.4\%, report that their businesses have recognized measurable benefits as a result of big data initiatives. A significant $80.7 \%$ of executives described their big data investments as successful, with $21 \%$ of executives confirming big data to have been both disruptive and transformational for their firm. In spite of the positive early results, executives still see lingering cultural impediments as a barrier to recognizing the full value and full business adoption of big data in the corporate world. 52.5\% of executives report that organizational barriers prevent realization of broad business adoption of big data initiatives. Impediments include lack of organizational alignment, business and/or technology resistance, and lack of middle management skill set as the most common factors. 18\% cite lack of a comprehensible big data strategy (Anon, 2017). Firms are struggling to create data-driven cultures (69.4\%), generate new avenues for innovation and 
disruption (64.5\%), quicken the speed with which new competencies and services are deployed $(64.5 \%)$, launch new product and service offerings $(62.9 \%)$, "monetize" big data through increased revenues and new revenue sources $(54.8 \%)$, and transform and reposition their business for the future (51.6\%). 72.6\% are seeking to decrease expenses through operational cost efficiencies-with $49.2 \%$ reporting successful results from their cost reduction efforts as a result of big data investments (Anon, 2017).

The explosion of big data has created a new executive position, Chief Data Officer. A majority of organizations report having created a Chief Data Officer (55.9\%). While 56\% see the role as largely defensive and reactive in scope- $48.3 \%$ believe that the key role of the Chief Data Officer should be to drive innovation and establish a data driven culture, and $41.4 \%$ indicate that the role of the CDO should be to manage and influence data as an enterprise business asset (Anon, 2017).

Executives in the survey fear that disruption is quickly approaching on the immediate horizon. A robust $46.6 \%$ of executives express the view that their firm may be at risk of major disruption in the coming decade. They envision a future where "change is coming faster" and it may be "transform quickly or die". In addition to the challenges of big data, these companies see disruption coming from a variety of emerging capabilities, including Artificial Intelligence or machine learning (88.5\%), digital technologies $(75.4 \%)$, cloud computing $(65.6 \%)$, Block chain $(62.3 \%)$. Spending for big data and business analytics technology and services is predicted to surge from \$130.1 billion in 2016 to \$203 million in 2020, a compound annual growth rate of 11.7 percent, according to market researcher IDC (Whiting, 2017).

\section{Method}

\subsection{Defining the Search Parameters}

After a review of job boards and career sites, Ihiremarketing.com was selected for this research based on its extensive listings and search capabilities. The top six U.S. cities for marketing positions were identified through a preliminary search as New York, San Francisco, Los Angeles, Chicago, Dallas and Atlanta. The geographic area of each city was limited to a 100 mile radius from the city center. The search criteria for the term "marketing professional" was defined as, Marketing Professional, with at least 5 years' experience up to senior experience, excluding CMO, Executive or Officer level positions. Total marketing jobs matching those criteria in all six cities totaled 12,769.

\subsubsection{Definition of Key Search Terms}

Several preliminary searches were conducted citing over 5,000 job descriptions to identify the top six most commonly cited marketing skills. Once the top six skills were identified and defined by the job descriptions, a search of each city based on the set criteria was conducted.

1) Data - individual facts, statistics, or items of information;

2) Big data - data held in such large amounts that it can be difficult to process;

3) Analytics - the analysis of data, typically large sets of business data, by the use of mathematics, statistics, and computer software;

4) Social Media - websites and online communications used by groups to share information, develop social \& professional contacts;

5) Excel-MS suite of productivity tools and the most widely used spreadsheet in the world;

6) Budgets - an estimate, often itemized, of expected income \& expense for a given period. 


\subsubsection{Data Collection}

Data was collected on each city identified based on the defined criteria for marketing professional and the six key search term skills.

\section{Result}

The research found 39\% all marketing positions in the defined search criteria listed "big data" as a required skill in the combined six cites. San Francisco with the largest number of positions listed $(3,260)$ also had the highest requirement for big data skills at $47 \%$. They also had the highest requirements for both Data 43\%, and Analytics 42\%. Dallas had the lowest requirement for big data at 33\% of 910 positions. It is interesting to note the term "Big data" was cited $39 \%$ and surpassed the term "Data", which was cited $35 \%$ across all 12,796 positions. The term "Social media" was the overall most cite skill across all six cities at 44\%. New York had the highest skill listing of Social Media at $47 \%$.

Table 1. New York 4,009 Total Positions Examined

\begin{tabular}{lll}
\hline Skill & Quantity & Percentage \\
\hline Data & 1,289 & $32 \%$ \\
Big data & 1466 & $37 \%$ \\
Analytics & 1400 & $35 \%$ \\
Social Media & 1881 & $47 \%$ \\
Excel & 1012 & $25 \%$ \\
Budgets & 862 & $22 \%$ \\
\hline
\end{tabular}

Table 2. Chicago 1,677 Total Positions Examined

\begin{tabular}{lll}
\hline Skill & Quantity & Percentage \\
\hline Data & 544 & $32 \%$ \\
Big data & 590 & $35 \%$ \\
Analytics & 599 & $36 \%$ \\
Social Media & 710 & $42 \%$ \\
Excel & 466 & $28 \%$ \\
Budgets & 395 & $24 \%$ \\
\hline
\end{tabular}

Table 3. Atlanta 884 Total Positions Examined

\begin{tabular}{lll}
\hline Skill & Quantity & Percentage \\
\hline Data & 289 & $33 \%$ \\
Big data & 320 & $36 \%$ \\
Analytics & 280 & $32 \%$ \\
Social Media & 330 & $37 \%$ \\
Excel & 184 & $21 \%$ \\
Budgets & 189 & $21 \%$ \\
\hline
\end{tabular}


Table 4. Dallas 910 Total Positions Examined

\begin{tabular}{lll}
\hline Skill & Quantity & Percentage \\
\hline Data & 263 & $33 \%$ \\
Big data & 301 & $33 \%$ \\
Analytics & 235 & $26 \%$ \\
Social Media & 339 & $37 \%$ \\
Excel & 212 & $23 \%$ \\
Budgets & 170 & $19 \%$ \\
\hline
\end{tabular}

Table 5. San Francisco 3,260 Total Positions Examined

\begin{tabular}{lll}
\hline Skill & Quantity & Percentage \\
\hline Data & 1,391 & $43 \%$ \\
Big data & 1,539 & $47 \%$ \\
Analytics & 1,356 & $42 \%$ \\
Social Media & 1,486 & $46 \%$ \\
Excel & 404 & $22 \%$ \\
Budgets & 626 & $19 \%$ \\
\hline
\end{tabular}

Table 6. Los Angeles 2,029 Total Positions Examined

\begin{tabular}{lll}
\hline Skill & Quantity & Percentage \\
\hline Data & 654 & $32 \%$ \\
Big data & 733 & $36 \%$ \\
Analytics & 641 & $22 \%$ \\
Social Media & 928 & $46 \%$ \\
Excel & 559 & $28 \%$ \\
Budgets & 423 & $21 \%$ \\
\hline
\end{tabular}

Table 7. 12,796 Total Positions All 6 Cities

\begin{tabular}{ll}
\hline Skill & Percentage \\
\hline Data & $35 \%$ \\
Big data & $39 \%$ \\
Analytics & $35 \%$ \\
Social Media & $44 \%$ \\
Excel & $25 \%$ \\
Budgets & $21 \%$ \\
\hline
\end{tabular}

\section{Discussion}

The data presented in this paper shows a clear and dramatic increase in the term "big data" as listed in job requirements for marketing professionals. The increase is substantial since the term "big data" is relatively new and only recently adopted industry wide in the last seven years. This author was unable to find any data or similar studies looking at the adoption of big data skills in job requirements.

Academia must ask itself if they are successfully preparing students for the explosion of data that is rapidly changing the skills demanded not just on marketing but all business professions? "What's really going to make big data go mainstream is the ability to connect not just with data scientists and 
technologists but business people" (Hewlett, 2017).

IBM, SAP and most major big data vendors offer training and certificate programs along with having partnership programs with Universities to accelerate closing the big data skill gap (Ibm.com, 2017).

College curriculums at the undergraduate and graduate level have taken step to address the rapidly change skill requirement for data analytics across all industries.

Future research on this topic would include repeating this study in the next 3-5 years to measure the change in skill sets required in the marketing industry. Additional research could extend into other areas of business, where big data analysis is also critical to success.

Table 8. Six City Comparisons

\begin{tabular}{|c|c|c|c|c|c|c|c|}
\hline & Total Jobs & Data & Big data & Analytics & Social Media & Excel & Budgets \\
\hline \multirow[t]{2}{*}{ Chicago } & 1677 & 544 & 590 & 599 & 710 & 466 & 395 \\
\hline & & $32 \%$ & $35 \%$ & $36 \%$ & $42 \%$ & $28 \%$ & $24 \%$ \\
\hline \multirow[t]{2}{*}{ New York } & 4009 & 1289 & 1466 & 1400 & 1881 & 1012 & 862 \\
\hline & & $32 \%$ & $37 \%$ & $35 \%$ & $47 \%$ & $25 \%$ & $22 \%$ \\
\hline \multirow[t]{2}{*}{ Dallas } & 910 & 263 & 301 & 235 & 339 & 212 & 170 \\
\hline & & $29 \%$ & $33 \%$ & $26 \%$ & $37 \%$ & $23 \%$ & $19 \%$ \\
\hline \multirow[t]{2}{*}{ Los Angeles } & 2029 & 654 & 733 & 641 & 928 & 559 & 423 \\
\hline & & $32 \%$ & $36 \%$ & $32 \%$ & $46 \%$ & $28 \%$ & $21 \%$ \\
\hline \multirow[t]{2}{*}{ San Francisco } & 3260 & 1391 & 1539 & 1356 & 1486 & 704 & 626 \\
\hline & & $43 \%$ & $47 \%$ & $42 \%$ & $46 \%$ & $22 \%$ & $19 \%$ \\
\hline \multirow[t]{2}{*}{ Atlanta } & 884 & 289 & 320 & 280 & 330 & 184 & 189 \\
\hline & & $33 \%$ & $36 \%$ & $32 \%$ & $37 \%$ & $21 \%$ & $21 \%$ \\
\hline \multirow[t]{2}{*}{ Totals } & 12769 & 4430 & 4949 & 4511 & 5674 & 3137 & 2665 \\
\hline & & $35 \%$ & $39 \%$ & $35 \%$ & $44 \%$ & $25 \%$ & $21 \%$ \\
\hline
\end{tabular}

\section{Acknowledgement}

To my wife Beverly, who makes everything I do possible.

\section{References}

Anon. (2017). Evans Data Corporation. Available on Big data and Advanced Analytics Survey 2015.
Forbes.com.
Forbes
Welcome.
Retrieved
from https://www.forbes.com/sites/bernardmarr/2015/09/30/big-data-20-mind-boggling-facts-everyonemust-read/\#5ce906fa17b1

Frost.com. (2017). Big data and Analytics. Retrieved from https://ww2.frost.com/research/industry/digital-transformation/big-data-analytics/

HewlettPackard.com. (2017). Vertica Advance Analytics. Retrieved from https:/www.saas.hpe.com/en-us/software/big-data-software-services

Ibm.com. (2017). IBM Big data-What is Big data-United States. Retrieved from https://www.ibm.com/big-data/us/en/

Insights, S., Insights, B., \& Data, W. (2017). What is Big data and why it matters. Retrieved from https://www.sas.com/en_us/insights/big-data/what-is-big-data.html\#dmhistory 
$\begin{array}{lllll}\text { McKinsey } & \text { \& } & \text { Company. } & \text { (2017). } & \text { Retrieved }\end{array}$ http://www.mckinsey.com/business-functions/digital-mckinsey/our-insights/big-data-the-next-fron tier-f

Sas.com. (2017). Big data, Bigger Marketing. Retrieved from https://www.sas.com/en_us/insights/big-data/big-data-marketing.html

Schmidt, S. (2012). Data Is Exploding: The 3V's of Big data. Retrieved from http://www.businesscomputingworld.co.uk/data-is-exploding-the-3vs-of-big-data/

Whiting, R. (2017). The 2017 Big data 100. https://doi.org/10.3113/JSOA.2017.0086 